\title{
A review on the emerging use of targeted therapy by Nanoparticles and Nano medicine
}

\author{
NOOR AIN ${ }^{1}$, Noor -Ul-Ain ${ }^{2}$, and Haiqa Ahsan ${ }^{3,4}$ \\ ${ }^{1}$ Affiliation not available \\ ${ }^{2}$ Department of pharmacy, The University of Faisalabad \\ ${ }^{3}$ Department of chemistry, Department of Pharmacy, Government College University \\ ${ }^{4}$ The University of Faisalabad
}

June 11, 2021

\begin{abstract}
There are number of innovations have been made in the field of medicine to give the ill patient the best of the treatment. As such the use of nanoparticles has also become an increasing demand because of their remarkable actions on the edge of targeted drug therapy. There are number of disorders that must be treated by the way as a specific treatment for the diseases like cancer in which the main purpose of the formation of these particles is to protect the healthy cells from the harmful effects of the drugs. And this could be only possible by making the drugs as specific in their action so these can only target the cells of interest as the abnormal one. Nano medicines are small particles which when given to the patient cause san improvement in the abnormality by better absorption and better distribution to the cells like abnormal one. So it is need of hour to make such drugs which have remarkable effects on the diseased part of body.
\end{abstract}

\section{Hosted file}

nanoparticles article-converted.pdf available at https://authorea.com/users/346729/articles/ 525848-a-review-on-the-emerging-use-of-targeted-therapy-by-nanoparticles-and-nanomedicine 